\title{
Vocábulos fundantes de Clarice Lispector extraídos de duas obras da autora e características de normalização em suas respectivas traduções
}

\author{
Thereza Cristina de Souza Lima \\ Centro Universitário Internacional Uninter (UNINTER), Curitiba, Paraná, Brasil \\ thereza.1@uninter.com, tcslcristina@gmail.com \\ http://orcid.org/0000-0002-6955-4840
}

DOI: http://dx.doi.org/10.21165/el.v47i2.1926

\begin{abstract}
Resumo
A presente pesquisa tem como objetivo observar o comportamento de tradutores diferentes em face de fragmentos (re)aproveitados e semelhantes extraídos de duas obras de Clarice Lispector. Outro objetivo é verificar as escolhas desses tradutores frente a dois vocábulos recorrentes da autora: silêncio e olhos. Temos como arcabouço teórico os Estudos da Tradução baseados em corpus (BAKER, 1993, 1995, 1996, 1999, 2004; estudos sobre normalização (SCOTT, 1998) a Linguística de Corpus (BERBER SARDINHA, 2004) e a fortuna crítica da autora (NUNES, 1995; SÁ, 2000). Como procedimento metodológico, a pesquisa foi realizada por meio de uma combinação de investigações semimanuais e computadorizadas. Com base em Scott (1998), examinamos a tradução dos vocábulos selecionados em relação à normalização. Os resultados finais apontam para tendência à normalização por parte de ambos os tradutores em pauta.
\end{abstract}

Palavras-chave: estudos da tradução; Linguística de corpus; normalização.

Meaningful words of Clarice Lispector extracted from two books of the author and characteristics of normalization in their respective translations

\begin{abstract}
The present research aims to observe the behavior of different translators facing similar and reused fragments extracted from two books written by Clarice Lispector. The other objective is to verify these translators' choice concerning two of the authors' reoccurring words: silence and eyes. We have, as theoretical framework, Corpus-based translation studies (BAKER, 1993, 1995, 1996, 1999, 2004); studies on normalization (SCOTT, 1998); Corpus linguistics (BERBER SARDINha, 2004) and the author's critical heritage (NUNES, 1995; SÁ, 2000). As methodological procedure, the research was carried out by means of a combination of semimanual and computerized investigation. Drawn on Scott (1998), we examined the translation of the selected words in relation to aspects of normalization. The final results point at a certain tendency to normalization in relation to both translators in question.
\end{abstract}

Keywords: translation studies; Corpus linguistics; normalization.

\section{Introdução}

Clarice Lispector é uma escritora de destaque em nossa literatura. Considerada enigmática, introspectiva, aborda em uma linguagem peculiar, muitas vezes de difícil compreensão, temas como a vida, a morte, o silêncio, os olhos, entre outros. A linguagem de Clarice Lispector é tão peculiar que, na visão de Alceu Amoroso Lima (1964, orelha do romance $O$ Lustre), "ninguém escreve como Clarice Lispector. Clarice Lispector não 
escreve como ninguém, só seu estilo mereceria um ensaio especial. É uma chave diferente a qual o leitor custa a adaptar-se".

Diante da referida "linguagem peculiar" e de difícil compreensão, faz-se necessária uma investigação a respeito das soluções apresentadas pelo tradutor Giovanni Pontiero ao traduzir, para o inglês britânico, as crônicas que Clarice Lispector escreveu e publicou no Jornal do Brasil entre 1967 e 1973, que compõem a obra A Descoberta do Mundo (DM), nosso texto de partida 1 (TP1), cujo título Pontiero traduziu como Discovering the World ( $D W)$, nosso texto de chegada 1 (TC1). A mesma investigação também se faz necessária no romance Uma Aprendizagem ou o Livro dos Prazeres (ALP), nosso texto de partida 2 (TP2), traduzido para o inglês americano por Richard A. Mazzara e Lorri A. Parris com o título An Apprenticeship or the Book of Delights (ABD), nosso texto de chegada 2 (TC2).

Com base na pesquisadora Ranzolin (1985), observamos que Clarice realiza um (re)aproveitamento de partes das crônicas da $D M$ no romance $A L P$, ou, à maneira inversa, o (re)aproveitamento de partes de seu livro $A L P$ nas crônicas da $D M$. Como tais obras foram traduzidas por diferentes profissionais, é possível analisar o comportamento tradutório de cada um deles, frente a textos semelhantes, escritos em língua portuguesa e traduzidos para a língua inglesa. É importante ressaltar que nesses (re)aproveitamentos, a que nos referiremos como fragmentos, observamos deslocamentos, mudança de pronomes, reduções e ampliações de parágrafos, obedecendo ao fluxo irregular do discurso. Obviamente, isso acarreta mudanças substanciais para cada uma das respectivas traduções.

Observando mais detalhadamente a escritura clariciana, constatamos a importância da repetição e da carga emocional que seus vocábulos fundantes e palavraschave acarretam. Indubitavelmente, a repetição está presente em várias partes da escritura clariciana, inclusive nos fragmentos (re)aproveitados que também constituem um tipo de repetição. Clarice é consciente desse processo enriquecedor de seu estilo e na visão de Sá (2000), a escritora não tem medo da repetição. Assume-a realmente como uma técnica e um gosto pessoal: "a repetição me é agradável e repetição acontecendo no mesmo lugar termina cavando, pouco a pouco, cantilena enjoada, diz alguma coisa" (SÁ, 2000, p. 151).

O crítico Benedito Nunes (1995, p. 137), ainda sobre a repetição, afirma que ela "tanto aumenta a teia de significações, como pode também, em movimento inverso, reduzi-la. Onde se esgota a repetição, começa o silêncio". Para Clarice, tanto o silêncio em si quanto a explicitação do vocábulo "silêncio" são de primordial importância dentro da sua obra. Ambos, a repetição e o silêncio, relacionam-se à procura de um efeito de desgaste da palavra e da frase. Conforme mencionado anteriormente, por ser considerado fundante nas obras em pauta, selecionou-se para análise esse vocábulo e sua respectiva tradução.

Outro vocábulo aqui investigado, também considerado fundante pela fortuna crítica da autora é o vocábulo "olhos", presente significativamente nos fragmentos repetidos e (re)aproveitados, como no romance $A L P$, quando Lori e Ulisses finalmente entregam-se um ao outro:

Ele a beijou demoradamente até que ambos puderam se descolar um do outro, e ficaram se olhando sem pudor um nos olhos do outro. Ambos sabiam que já tinham ido longe demais. E ainda sentiam perigo de entregarem-se tão totalmente. Continuaram em 
silêncio. Foi então deitados no chão que se amaram tão profundamente que tiveram medo da própria grandeza deles (ALP, p. 146).

Segundo o dicionário de símbolos (CHEVALIER; GREERBRANT, 1990), na visão dos bambaras, durante o ato sexual a mulher se une ao homem pelos olhos e pelo sexo: a visão é o desejo, o olho é a cobiça e, enfim, o mundo do homem é o seu olho. Por isso, metaforicamente, o olho pode abranger noções de beleza, luz, mundo, universo, amor, silêncio, morte e vida.

Desta feita, tanto nas crônicas que compõem o TF1, quanto no romance que compõe o TF2, Clarice, em linguagem peculiar, emprega vocábulos recorrentes e significativos, que consideramos representativos dentro da grandeza das obras claricianas aqui investigadas, razão pela qual, com base na fortuna crítica da autora, selecionamos para análise, além do vocábulo "silêncio", o vocábulo "olhos", e suas respectivas traduções para a língua inglesa.

\section{Arcabouço teórico}

O objetivo da nossa pesquisa é investigar o fenômeno da normalização em textos traduzidos. Adotamos uma abordagem multidisciplinar baseada nos estudos da tradução e na linguística de corpus (BAKER, 1993, 1995, 1996; SCOTT, 1998); e também nos estudos literários (NUNES, 1995; SÁ, 2000). O arcabouço teórico metodológico principal baseia-se em Baker (1993, 1995, 1996, 1999, 2000) e nos estudos descritivos da tradução, cujo foco vira-se para a cultura de chegada, privilegiando o estudo de padrões que regem o sistema da tradução literária em interação com os demais sistemas de produção textual de uma dada cultura. É a partir do reconhecimento da tradução enquanto espaço que privilegia a cultura de chegada que Baker (1993) constitui a tradução como objeto de pesquisa per se, mas, para tanto, elege, também, como quadro metodológico para pesquisa, a abordagem da linguística de corpus. Justificamos nossa abordagem literária baseada em Nunes (1995) e Sá (2000), pelo fato de os referidos autores nos darem subsídios para analisar literariamente a linguagem de Clarice Lispector, os vocábulos recorrentes e preferenciais por ela utilizados selecionados- "silêncio" e "olhos" -, assim como as soluções apresentadas pelos profissionais que traduziram tais vocábulos.

Como a metodologia de Baker vale-se de teorias dos estudos da tradução e de teorias da linguística de corpus, cabe aqui, inicialmente, apresentarmos a definição de corpus dessa pesquisadora, que dá sustentação à nossa forma de investigação por envolver a observação de textos traduzidos:

Corpus agora significa fundamentalmente uma coletânea de textos que permitam leitura em formato eletrônico e que possibilitem análises processadas automaticamente em diversos modos; um corpus [...] inclui tanto textos falados como escritos e um corpus pode incluir um grande número de textos provenientes de várias fontes, produzidos por muitos escritores falantes e sobre uma variedade de tópicos [...] reunidos por uma finalidade específica e de acordo com critérios explícitos quanto ao seu desenho [...] representativo de uma dada área (BAKER, 1993, p. 241, tradução nossa). ${ }^{1}$

\footnotetext{
${ }^{1}$ Todas as traduções de citações são da autora do artigo.
} 
A proposta de Baker (1993) parte de duas principais correntes de pensamento, uma na área de investigação da tradução e outra na da linguística de corpus. A primeira baseia-se nas concepções de Toury (1978), para quem os estudos descritivos da tradução constituem o ramo da disciplina que deve fornecer uma metodologia coerente e procedimentos explícitos de pesquisa, de forma a permitir que os resultados de estudos descritivos individuais sejam expressos em termos de generalizações sobre 0 comportamento tradutório. A segunda vertente provém do linguista Sinclair (1991), o qual acredita que corpora computadorizados conseguem minimizar, em parte, as limitações do pesquisador e sua dependência da intuição. A partir dessas duas correntes de pensamento, Baker (1993) estabelece a tradução como objeto de pesquisa da disciplina, cujo objetivo principal passa a ser a identificação de traços do texto traduzido que levarão ao entendimento do que é e de como funciona a tradução.

Ainda com base em Baker (1993, p. 243), observamos que a pesquisadora menciona quatro categorias ou estratégias que "tipicamente ocorrem em textos traduzidos... e que não são resultado da interferência de sistemas linguísticos específicos". Mais especificamente, essas categorias são:

a) Normalização: A tendência do tradutor em exagerar as características da língua de chegada, adaptando a linguagem do texto original aos padrões típicos da linguagem do texto traduzido. A normalização pode ocorrer ao nível da microestrutura e afetar a macroestrutura do romance, como, segundo Scott (1998), aconteceu na obra espanhola Don Quixote em sua tradução para a língua holandesa. Baker (1996) afirma que há uma relação entre a normalização e o status da língua alvo, isto é, quanto mais alto o status da língua fonte, menor a tendência à normalização. Além disso, Baker (op. cit.) observa que a normalização é mais evidente quando se relaciona a formas gramaticais, à pontuação e a padrões de combinação de palavras, ou seja, de colocações.

b) Explicitação: A tendência do tradutor de tornar a linguagem mais explícita, mais clara para o leitor do texto traduzido. A referida estratégia justificaria o fato de os textos traduzidos serem, em média, 10\% mais longos do que os textos originais.

c) Simplificação: A tendência do tradutor de simplificar a linguagem usada na tradução, ou seja, tornar a leitura mais fácil (não necessariamente mais explícita) para o leitor. A simplificação envolve a análise do comprimento de sentença, ambiguidade, pontuação, densidade lexical e razão forma/ocorrência, ou seja, uma medida da variedade de vocabulário usada num texto ou corpus, possibilitando verificar se o texto traduzido apresenta um vocabulário mais ou menos variado do que o texto original na mesma língua. $\mathrm{O}$ uso de vocabulário menos variado é um traço dos textos direcionados para falantes não nativos de uma língua, para torná-los mais fáceis de processar.

d) Nivelamento: A referida estratégia diz respeito à tendência em encontrar um equilíbrio, em não exagerar características da linguagem do texto original, nem características da linguagem do texto traduzido. O nivelamento envolveria a tendência em trazer o texto traduzido para uma linguagem padrão sem privilegiar a língua de partida.

Em tese apresentada à Universidade de Liverpool, Maria Nélia Scott (1998) investiga a estratégia de normalização, utilizada por Pontiero ao traduzir o romance A Hora da Estrela, de Clarice Lispector, associando-a ao que Venutti (1995, p. 31) refere criticamente como "domesticação", ou seja, "tornar o texto estrangeiro claro... domesticando-o". Na mencionada pesquisa, Scott estabelece 11 características da 
normalização que são: 1) comprimento do texto e da sentença; 2) pontuação; 3) estruturas sintaticamente complexas; 4) ambiguidade; 5) imprecisão de expressão; 6) metáforas incomuns; 7) mudança de linguagem coloquial para formal; 8) omissões e/ou adições; 9) troca de palavras menos comuns por mais comuns; 10) outras mudanças na tradução; 11) padrões de repetição.

Baker (1995) também observa que os corpora utilizados para pesquisa podem ser: 1) Paralelos: consistem de textos originais numa língua de partida e suas respectivas traduções numa língua de chegada; 2) Multilíngues: conjuntos de dois ou mais corpora monolíngues, que permitem estudar os itens e os traços linguísticos no ambiente da língua tal como produzida originalmente; 3) Comparáveis: cujo papel na disciplina de estudos da tradução é o de identificar padrões específicos de textos traduzidos.

Empregaremos dois corpora paralelos, por serem os mais indicados para nossa pesquisa, pois possibilitam que o foco deixe de ser prescritivo e passe a ser descritivo. Em outras palavras, permitem que o pesquisador observe e descreva as escolhas do tradutor, frente às dificuldades inerentes ao processo tradutório. Segundo Baker (1995, p. 231), este tipo de corpus desempenha "um papel crucial na exploração de normas de tradução em contextos socioculturais e históricos".

Quanto à composição dos corpora, selecionamos dois pares de obra de Clarice Lispector, originalmente escritos em língua portuguesa, e as respectivas traduções para a língua inglesa. Também compilamos fragmentos semelhantes (re)aproveitados pela autora, extraídos de ambos os corpora. Desse modo, a constituição dos três corpora da presente pesquisa corresponde a:

Corpus 1: constituído pelo subcorpus na língua fonte 1.1: A Descoberta do Mundo $(D M)$, de Clarice Lispector, Rio de Janeiro: Editora Rocco, 1999, $3^{\mathrm{a}}$ edição, 478 páginas, 172.143 palavras; e, na língua meta, pelo subcorpus 1.2: Discovering the World $(D W)$, tradução de Giovanni Pontiero, Manchester: Carcanet Press, 1992, 652 páginas, 194.167 palavras.

Corpus 2: constituído pelo subcorpus na língua fonte 2.1: Uma Aprendizagem ou O Livro dos Prazeres (ALP), de Clarice Lispector, Rio de Janeiro: Editora José Olímpio, 1969, 155 páginas, 36.385 palavras; e, na língua meta, pelo subcorpus 2.2: An Apprenticeship or The Book of Delights $(A B D)$, tradução de Richard A. Mazzara e Lorri A. Parris, Austin: University of Texas Press, 1986, 126 páginas, 40.321 palavras.

Corpus 3: fragmentos repetidos e reaproveitados pela autora: constituído, na língua fonte, pelo subcorpus 3.1, com 7.343 palavras, contendo fragmentos semelhantes extraídos do TF1 $(D M)$; também na língua fonte, pelo subcorpus 3.2, com 7.880, contendo fragmentos semelhantes extraídos do TF2 ( $A L P)$; bem como, na língua meta, pelo subcorpus 3.3, com 7.871 palavras contendo fragmentos traduzidos por Pontiero, os quais foram extraídos do TM1 $(D W)$ e, também na língua meta, pelo subcorpus 3.4, com 8.379 palavras, contendo fragmentos traduzidos por Mazzara e Parris, os quais foram extraídos do TM2 $(A B D)$.

Para facilitar a visualização, apresentamos o quadro abaixo, com a composição dos corpora na presente pesquisa: 


\begin{tabular}{|l|c|c|c|c|}
\hline & \multicolumn{2}{|c|}{ CORPUS 1 } & \multicolumn{2}{c|}{ CORPUS 2 } \\
\hline & TF1 $(D M)$ & TM1 $(D W)$ & TF2 $(A L P)$ & TM2 $(A B D)$ \\
\hline N. ${ }^{\circ}$ de palavras & 172.143 & 194.167 & 36.385 & 40.321 \\
\hline
\end{tabular}

\begin{tabular}{|l|c|c|c|c|}
\cline { 2 - 5 } \multicolumn{1}{c|}{} & $\begin{array}{c}\text { Subcorpus 3.1 } \\
\text { FF1 extraído de } \\
(D M)\end{array}$ & $\begin{array}{c}\text { Subcorpus 3.2 } \\
\text { FF2 extraído de } \\
(A L P)\end{array}$ & $\begin{array}{c}\text { Subcorpus 3.3 FM1 } \\
\text { extraído de }(D W)\end{array}$ & $\begin{array}{c}\text { Subcorpus 3.4 FM2 } \\
\text { extraído de }(A B D)\end{array}$ \\
\hline $\begin{array}{l}\text { N. }{ }^{\circ} \text { de } \\
\text { palavras }\end{array}$ & 7.343 & 7.800 & 7.871 & 8.379 \\
\hline
\end{tabular}

Levando em conta a importância dos vocábulos "silêncio" e "olhos" na escritura clariciana e o fato de poderem ser considerados vocábulos recorrentes e preferenciais em nossos corpora, segundo levantamento gerado pela Wordlist do programa WordSmith Tools, passamos a observar as concordâncias do referido vocábulo, à direita e à esquerda no nível da frase e no do parágrafo, objetivando listar as combinações frequentes de Lispector e analisar as traduções efetuadas pelos tradutores Pontiero em nosso TC1 e Mazzara e Parris em nosso TC2.

Dada a sua alta recorrência, seria inexequível extrair todas as concordâncias dos referidos vocábulos nas duas obras que compõem nossos corpora um e dois (TP1 e TP2) e suas respectivas traduções (TC1 e TC2). Por esta razão, efetuamos as concordâncias nos fragmentos semelhantes encontrados em nossos corpora e selecionamos exemplos para ilustrar nosso trabalho.

\section{Concordâncias e análises dos vocábulos "silêncio" e "olhos"}

Conforme explicitado anteriormente, Scott (1998) investigou a estratégia de normalização utilizada por Pontiero ao traduzir o romance de Clarice Lispector $A$ Hora da Estrela e estabeleceu 11 características da normalização.

Baseando-nos em Scott (1998), identificamos três características como as mais pertinentes para nossa pesquisa. São elas: metáfora incomum em relação ao silêncio; alterações em estruturas complexas em relação a olhos e repetição em relação a ambos, silêncio e olhos.

\section{Metáfora incomum e o silêncio}

Pensar metaforicamente é central à nossa existência, faz parte da nossa vida diária não apenas na língua, mas em pensamento e ação. "A metáfora é o exemplo de palavra fora do seu sentido normal, por efeito de analogia. À sequência de metáforas se dá o nome de alegoria" (SACCONI, 1989, p. 394). Scott (1998, p. 164, tradução nossa) concorda com Lakoff e Johnson, no sentido de que "nosso sistema conceitual comum, em termos do qual nós pensamos e agimos, é fundamentalmente metafórico por natureza" ${ }^{2}$.

\footnotetext{
2 "[...] our ordinary conceptual system, in terms of which we both think and act, is fundamentally
} metaphorical in nature". 
Poderíamos considerar a linguagem de Clarice Lispector como uma alegoria, uma vez que a autora utiliza uma sequência de metáforas, muitas delas consideradas incomuns, contribuindo para prender o interesse do leitor no texto.

Exemplos de normalização e respectiva análise em relação à metáfora incomum na tradução do "silêncio"

FF1 ${ }^{3}$ - [...] faz de conta que uma veia não se abrira e faz de conta que sangue escarlate não estava em silêncio branco escorrendo e que ela não estivesse pálida de morte,

FM1- [...] pretend a vein had not been opened to allow crimson blood to trickle in white silence and that she was not deathly pale.

FF2 - [...] faz de conta que uma veia não se abrira e faz de conta que dela não estava em silêncio alvíssimo escorrendo sangue escarlate, e que ela não estivesse pálida de morte

FM2- [...] she pretended that a vein had not burst open and that scarlet drops of blood were not dripping from her in the brightest silence and that she was not deathly pale,

FF1- E Deus se liquefez enfim em chuva? Não. Nem quero. Por seco e calmo ódio, quero isso mesmo, este silêncio feito de calor que a cigarra rude torna sensível.

FM1- Out of dry and tranquil hatred, this is what I really want, this silence formed by heat which the rustic cicada can make one feel.

FF2- Por seco e calmo ódio, quero isso mesmo, este silêncio feito de calor que a cigarra rude torna sensível.

FM2- What I want from my dry, calm hatred is exactly this silent heat made sensitive by the rustic grasshopper.

Nos dois exemplos acima, notamos que no FM1 as metáforas "silêncio branco" e "silêncio feito de calor" são traduzidas literalmente por Pontiero: "white silence", e "silence formed by heat". No entanto, no FM2, observamos que os tradutores tentaram usar metáforas mais comuns: "brightest silence", e "silent heat". As escolhas de ambos os tradutores poderiam corresponder a traços de normalização, uma vez que tornam a linguagem mais clara para o leitor.

\section{Alterações em estruturas complexas e os "olhos"}

A ordem das palavras nas frases contribui expressivamente para a compreensão do leitor, uma vez que, "a ordem dos elementos em uma estrutura pode ser modificada para ajudar a carga de memória e facilitar o processamento" (QUIRK et al., 1985 apud SCOTT, 1998, p. 150, tradução nossa).

Exemplo de normalização e respectiva análise em relação à metáfora incomum na tradução dos "olhos"

\footnotetext{
${ }^{3}$ FF1 corresponde a Fragmento fonte 1; FM1 corresponde a Fragmento meta 1; FF2 corresponde a fragmento fonte 2 e FM2 corresponde a fragmento meta 2 .

${ }^{4}$ The order of the elements in a structure can be changed to aid memory load and easy processing.
} 
FF1- Abaixa a cabeça dentro do brilho do mar, e retira uma cabeleira que sai escorrendo toda sobre os olhos salgados que ardem.

FM1- She lowers her head into the gleaming waters and re-emerges, her hair dripping salt-water which causes her eyes to smart.

FF2- Abaixa a cabeça dentro do brilho do mar, e retira uma cabeleira que sai escorrendo toda sobre os olhos salgados que ardem.

FM2- She lowers her head into the sparkling sea and pulls back a lock of hair dripping water over her eyes, which are burning from the salt.

Observamos, no exemplo acima, que a opção de Mazzara e Parris no FM2 apresenta alguns acréscimos; porém, parece-nos de mais fácil compreensão para o leitor na LM que a opção de Pontiero no FM1, que qualifica a água com o uso do adjetivo composto "salt-water". Também notamos que ambos, o tradutor individual e a equipe de tradutores, optam por distanciar e desfazer a hipálage empregada por Clarice relativa à $^{5}$ sequência "brilho do mar" e "olhos salgados". Tais opções ocasionam certas alterações na estrutura complexa empregada por Clarice, e poderiam caracterizar aspectos de normalização. Contudo, a opção de Mazzara e Parris mostra uma estratégia mais facilitadora para a compreensão do leitor na LM, comparada à decisão de Pontiero.

\section{Repetição em relação a ambos, "silêncio" e "olhos"}

A repetição em textos tem sido constantemente estudada (SCOTT, 1998; BERBER SARDINHA, 1997), e é considerada um recurso que visa a manter a coesão e a coerência nos textos.

Scott (1998, p. 174) cita Halliday e Hasan que empregam o termo "reiteração", ou seja, "a repetição, um sinônimo, um quase sinônimo [...] ou uma palavra geral", com o propósito de criar relações entre as sentenças, construir coesão e dar ao leitor um senso de direção no que diz respeito à obra em questão. A pesquisadora cita também Gutwinski (1998 apud SCOTT, 1998), que, por sua vez, dedicou-se à investigação de aspectos de coesão em relação à repetição lexical e observou o papel paradoxal da repetição, pois, ao mesmo tempo em que se cria a sensação de "mesmice", acrescenta-se também alguma coisa nova ao texto. Em outras palavras, se, por um lado, a repetição é útil para clarear a ambiguidade que poderia ocorrer no texto, por outro lado, o acúmulo de repetições adiciona-lhe camadas extras de significado.

Concernente à escrita de Clarice Lispector, supomos que a repetição apresente tamanha relevância para a autora que ela repete, inúmeras vezes, não apenas vocábulos, mas também fragmentos inteiros em duas ou mais obras, por exemplo, nos fragmentos semelhantes e (re)aproveitados em pauta, repetidos tanto como crônicas na $D M$, quanto como parte do romance $A L P$.

Na visão de Benedito Nunes (1995, p. 136), a autora

[...] tem na repetição o seu traço de mais largo espectro [...] o emprego reiterado dos mesmos termos, das mesmas frases [...] substantivos, verbos e advérbios [...] sempre

\footnotetext{
${ }^{5}$ A hipálage é uma figura sintática e semântica da transposição das relações naturais de dois elementos em uma proposição.
} 
desempenham funções expressivas e produzem determinados efeitos, quer no uso da palavra, quer no sentido do próprio discurso.

Desse modo, os termos repetidos estabelecem uma gradação entre diferentes significações que se unem em cadeia, reforçando mutuamente a proliferação de um significado inexaurível, podendo, por outro lado, reduzir a teia de significações, o que levaria ao "silêncio", vocábulo recorrente e preferencial de Lispector, investigado no presente trabalho.

No exemplo abaixo, Clarice repete o vocábulo "silêncio" três vezes seguidas de uma forma que caracterizaria uma figura de linguagem relacionada à repetição, a anadiplose ${ }^{6}$ :

FF1- Como estar ao alcance dessa profunda meditação do silêncio. Desse silêncio sem lembrança de palavras [...] É um silêncio que não dorme.

FM1- How is one to attain this profound meditation carried out in silence? A silence with no memory of words. [...] This is a silence which never sleeps.

FF2- Como estar ao alcance dessa profunda meditação do silêncio. Desse silêncio sem lembrança de palavras [...] É um silêncio que não dorme.

FM2- How to come within reach of that profound meditation of silence? Of that silence beyond the memory of words? [...]It's a silence, Ulysses, that doesn't sleep.

Observamos, no exemplo acima, que a autora repete e personifica o "silêncio" com as expressões: "profunda meditação do silêncio", "silêncio sem lembrança de palavras" e "é um silêncio que não dorme". No FM1, Pontiero também utiliza as referidas figuras de linguagem, porém, acrescenta o verbo "carry out": "How is one to attain this profound meditation carried out in silence?". O acréscimo do verbo "carry out" explicaria e facilitaria a compreensão do leitor na LM. Já os tradutores Mazara e Parris também repetem o vocábulo "silence" três vezes; contudo, "o silêncio sem palavras" foi traduzido como "silence beyond the memory of words", o que também poderia caracterizar uma explicitação dos tradutores no FM2, cujo propósito seria facilitar a compreensão do fragmento na LM.

Em exemplo de repetição com o vocábulo "olhos", a autora relaciona-o à antítese "morte/vida", vocábulos também considerados fundantes na escrita clariciana:

FF1- Depois os olhos ficaram úmidos: era felicidade, mas como sou mortal, como o amor pelo mundo me transcende. O amor pela vida mortal a assassinava docemente, aos poucos.

FM1- Then my eyes filled with tears: tears of happiness, but because I am mortal, my love for this world transcends me. My love for this mortal life gently killed it off little by little.

FF2- Depois seus olhos ficaram úmidos: era felicidade, mas como sou mortal, como o amor pelo mundo me transcende. O amor pela vida mortal a assassinava docemente, aos poucos.

\footnotetext{
${ }^{6}$ Define-se anadiplose como a repetição da palavra ou frase de período ou verso, no outro período ou no verso seguinte.
} 
FM2- Then her eyes started to tear: it was happiness. "But how mortal I am. How earthly love penetrates me." Love for mortal life was gradually, softly killing her.

Observamos, no exemplo acima, que Pontiero optou pela expressão "filled with tears" e que o substantivo "tears" é imediatamente repetido em substituição ao adjetivo "úmidos" empregado pela autora. Por outro lado, no FM2 Mazzara e Parris optam pelo uso da expressão started to tear, mas não repetem o vocábulo "tears". A repetição feita por Pontiero em FM1 pode ser vista como uma característica de normalização, objetivando facilitar a compreensão dos fragmentos na LM.

\section{Considerações finais}

Desde a publicação do seu primeiro livro, o romance Perto do Coração Selvagem, em 1944, Clarice Lispector atraiu a atenção dos críticos literários pelo seu estilo peculiar. A sua contínua busca pelo sentido da vida bem como a tentativa de penetrar no mistério que cerca o homem e de recriar o mundo partindo de suas próprias emoções ocasionaram um choque nos meios literários da época.

No fim dos anos 60, quando da publicação do romance $A L P$, Clarice já se encontrava definitivamente consagrada. Tornara-se leitura imprescindível em vários cursos universitários; porém, ainda assim, o referido romance agitou a crítica dos anos 1970 por ser uma obra polêmica que começava inusitadamente por uma vírgula, terminava com dois pontos, e ousava desnudar, de maneira radical, a intimidade profunda da mulher à procura da decifração do próprio enigma.

Nessa mesma época, mais precisamente a 19 de agosto de 1967, Clarice publicava suas primeiras crônicas no Jornal do Brasil. É de valia observar que a obra A Descoberta do Mundo $(D M)$ é formada por uma coletânea dessas crônicas e constitui-se em um de nossos corpora de pesquisa.

No tocante ao objetivo de nosso estudo voltado para aspectos de normalização, notamos que, em relação às duas obras de Clarice Lispector na LF, tanto Pontiero quanto Mazzara e Parris apresentam, de maneira consciente ou inconsciente, marcas destinadas a facilitar a compreensão do leitor dos respectivos textos na LM. Uma análise mais abrangente de todos os exemplos mencionados no presente estudo leva-nos a supor que ambos os tradutores de nosso TC1 e de nosso TC2 apresentam certa tendência à normalização. Contudo, observamos também que os resultados gerados a partir dos fragmentos (re)aproveitados evidenciam que a equipe de tradutores, ou seja, Mazzara e Parris, utiliza mais traços identificados como características de normalização ao traduzir $A B D$ do que Pontiero nos respectivos fragmentos traduzidos de $D W$.

É de valia observar que, uma vez que o romance $A B D$ foi traduzido por dois tradutores norte-americanos, visando ao público de cultura norte-americana, e a obra $D W$ foi traduzida por um tradutor britânico, visando ao público de cultura britânica, uma suposição que poderia ser considerada diz respeito à diferença entre normas de tradução que estariam regidas pelas respectivas culturas meta. Com base nos resultados da pesquisa, considerando a existência de normas de tradução vigentes nos Estados Unidos e na Grã-Bretanha, poder-se-ia levantar a suposição de que haveria certa tendência a um maior uso de estratégias visando facilitar a leitura do texto traduzido para o público norteamericano. Por sua vez, a tradução feita por Pontiero apontaria para certa tendência na 
Grã-Bretanha para um enfoque tradutório voltado para o texto fonte, e, em decorrência, com menor utilização de estratégias facilitadoras para o leitor britânico.

Outra inferência que poderia ser levantada reportar-se-ia a tendências particulares preferenciais e distintivas que indicariam o uso de padrões estilísticos próprios por parte de Mazzara e Parris ao recorrerem a recursos tradutórios encontrados nos corpora desta pesquisa, os quais poderiam ser vistos como traços de normalização.

Por seu turno, poder-se-ia também supor que o tradutor Pontiero apresentaria o uso de padrões de estilo individual mais aproximados do texto na LF e, consequentemente, com um menor emprego de recursos voltados para a normalização.

Cabe ressaltar a importância do trabalho dos tradutores para a divulgação das obras de Lispector no exterior, notadamente o de Giovanni Pontiero. Na opinião da pesquisadora Owen (1997, p. 136), a tradução das crônicas "constituía um desafio maior para o tradutor" ", exigindo um profissional com considerável experiência em traduzir a escrita de Lispector, devido à grande variação em estilos e registros existentes nas diferentes crônicas.

Em certa medida, como o romance e as crônicas pesquisados apresentam gêneros textuais diferentes, e as crônicas oferecem, segundo Owen, maiores dificuldades na tradução, tais fatores poderiam ter contribuído para uma maior tendência à normalização por parte de Pontiero, Entretanto, em comparação com a tradução do romance $A B D$ por Mazzara e Parris, os resultados não apontaram maiores indicações de características de normalização por parte de Pontiero.

\section{REFERÊNCIAS}

BAKER, M. Corpus linguistics and translation studies - Implications and applications. In: BAKER, M.; FRANCIS, G.; TOGNINI-BONELLI, E. Text and technology: in honour of John Sinclair. Amsterdam/Philadelphia: John Benjamins, 1993. p. 233-250.

Corpora in translation studies: an overview and some suggestions for future research. Target, Amsterdam/Philadelphia: John Benjamins, v. 7, n. 2, p. 223-243, 1995.

Corpus-based translation studies: the challenges that lie ahead. In: SOMERS, H. Terminology, LSP and translation studies in language engineering: in honour of Juan C. Sager. Amsterdam/Philadelphia: John Benjamins, 1996. p. 175-186.

BERBER SARDINHA, T. Automatic Identification of Segments in Written Texts. Unpublished $\mathrm{PhD}$ Thesis, University of Liverpool, Liverpool, 1997.

. Linguística de Corpus. São Paulo: Editora Manole Ltda. 2004.

CHEVAlIER, J.; GREERBRANT, A. Dicionário de Símbolos. Tradução de Vera da Costa e Silva et al. Rio de Janeiro: José Olympio, 1990.

LISPECTOR, C. A Descoberta do Mundo. Rio de Janeiro: Editora Rocco, 1987. Press, 1992.

Discovering the World. Tradução de Giovanni Pontiero, Manchester: Carcanet

7 “[...] posed a greater challenge to the translator". 
. Uma Aprendizagem ou O Livro dos Prazeres. Rio de Janeiro: Editora José Olimpio, 1969.

. An Apprenticeship or The Book of Delights. Tradução de Richard A. Mazzara e Lorri A. Parris. Austin: University of Texas Press, 1986.

NUNES, B. O Drama da Linguagem: uma leitura de Clarice Lispector. 2. ed. São Paulo: Ática, 1995.

OWEN, H. Giovanni Pontiero's Translation of Clarice Lispector's Discovering the World. In: ORERO, P.; SAGER, J. C. The Translator's Dialogue. Amsterdam/Philadelphia: John Benjamins Publishing Company, 1997.

RANZOLIN, C. R. Clarice Lispector Cronista: no Jornal do Brasil (1967-1973). 1985. 430 f. Dissertação (Mestrado em Literatura Brasileira) - Faculdade de Filosofia, Letras e Ciências, Universidade Federal de Santa Catarina, Florianópolis, 1985.

SÁ, O. A Escritura de Clarice Lispector. Petrópolis: Editora Vozes, 2000.

SCOTT, M. N. Normalisation and Reader's Expectation: A Study of Literary Translation with Reference to Lispector's A Hora da Estrela. 1998. 318 f. Tese (Doutorado em Filosofia) - Universidade de Liverpool, Liverpool, 1998.

TOURY, G. The Nature and Role of Norms in Translation. 1978. In: VENUTI, L. The Translation Studies Reader. London: Routledge Press, 2000. p. 198-213.

VENUTI, L. The Translator's Invisibility: A History of Translation. New York: Routledge, 1995.

Recebido em: 25/08/2017

Aprovado em: 21/03/2018 